\title{
Application of Short-Duration and High-Intensity Voltage Pulses for Food Processing and Storage Studies in Different Packaging Materials
}

\section{IJCRR}

Section: Healthcare

ISI Impact Factor (2019-20): 1.628

IC Value (2019): 90.81 SJIF (2020) $=7.893$

(c) (i) (3)

Copyright@IJCRR

\section{Sujatha $\mathbf{G}^{1}$, Sivakumar $\mathbf{T}^{2}$, Murali $\mathbf{D}^{3 *}$}

'Assistant Professor, Department of Food Process Engineering, College of Food and Dairy Technology, Koduvalli, Chennai-6oo 052, Tamil Nadu, India; 'Dean, Veterinary College and Research Institute, Orathanadu, Thanjavur-614625, Tamil Nadu, India; ${ }^{3}$ Professor, Department of Electrical \& Electronics Engineering, Government College of Engineering, Salem-636on, Tamil Nadu, India.

\section{ABSTRACT}

Introduction: The focus of food scientists and engineers is towards non-thermal technologies for food processing and preservation for retaining the fresh attributes of the product without compromising safety and quality. In this research work, one of the non-thermal approaches called the pulsed electric field (PEF) method has been employed for shelf-life studies of raw milk processing and preservation.

Objective: The main aim of this study is to investigate the shelf life studies of raw milk processing based on intense electric pulses of short duration and its packaging using various materials viz., glass bottles, lacquered tins, polyethene pouches and retort pouches.

Methods: To analyze the shelf life studies of raw milk processing, a non-thermal approach called the pulsed electric field method, which uses high voltage electric pulses for food processing, has been employed.

Results: The raw milk procured from nearby villages was processed using a pulsed electric field system and its shelf life was investigated using four different packaging materials. A voltage level of $35 \mathrm{kV} / \mathrm{cm}$ and 600 square pulses of pulse width $2.5 \mu$ sec enhanced the shelf-life to 28 days when stored in glass bottles.

Conclusion: The study suggests that the shelf life of processed milk samples is good in glass bottles followed by tins, retort pouches and polyethene pouches.

Key Words: Digital storage oscilloscope, Packaging materials, PEF processing, Raw cow milk, Shelf life

\section{INTRODUCTION}

Recently, the non-thermal approach for processing and preservation of food is preferred in food industries. This technique employs short duration pulses, of width in the range of microseconds, applied to the raw food placed between a set of electrodes. There is no significant heating of the food subjected to the high voltage pulses. The applied high voltage causes an intense electric field thereby inactivating microbial organisms. ${ }^{1,2}$ After the food processing, the packaging is important as it avoids post contamination. Certain foods are more sensitive to oxygen present in the air medium. The oxidization of fatty foods may produce off-flavours. Similarly, the loss of Vitamin $\mathrm{C}$ or discolouring of fruit juices may occur due to oxidization. The material used for packaging these kinds of foods that are exposed to oxygen should be able to prevent the transmission of oxygen into the food. The selection of pack- aging material depends upon technical suitability, availability and cost. In this proposed research work, high voltage (HV) electrical pulses of short duration are used for processing raw cow milk placed in the space between a set of electrodes. The presented work explains how the raw milk is processed using HV electric pulses of short width and how it is effectively stored in packages of different materials. The raw milk samples were collected from six different villages in and around Koduvalli village near Redhills, Chennai. The raw milk was processed through the lab-scale HV electric pulse based processing parallel plate batch treatment chamber and the milk so processed was effectively preserved in packages made of different materials.

The remaining part of the paper is planned into various sections. Section 2 explains the concept of the Pulsed Electric Field (PEF) system employed for raw milk processing. Sec-

\section{Corresponding Author:}

Murali D, Professor, Department of Electrical \& Electronics Engineering, Government College of Engineering, Salem-636011, Tamil Nadu, India; Email: muraliems@gmail.com

ISSN: 2231-2196 (Print) ISSN: 0975-5241 (Online)

Received: $31.01 .2021 \quad$ Revised: 13.03 .2021

Accepted: 03.05 .2021

Published: 12.09 .2021 
tion 3 describes the packaging of PEF processed milk. The shelf-life studies of milk collected from different sources are described in section 4. Finally, the conclusions of the proposed work are given in section 5 .

\section{MATERIALS AND METHODS}

\section{Concept of food processing using Non-thermal method}

The non-thermal method uses high voltage (HV) electric pulses for raw food processing. These HV electric pulses in turn produce a high-intensity electric field. This simple system of pulsed electric field (PEF) incorporates various essential components such as a scheme for producing an HV power supply, a bank of capacitors for energy storage, and HV resistor, a switch, processing chamber(s), voltage probes, current probes and temperature probes, and a cooling scheme. The overall PEF system is monitored by a control panel. The liquid food can be conducted through the processing equipment using a pump in the case of a continuous monitoring system. ${ }^{2}$ The concept and application of PEF technology have been explained by many authors in the literature. ${ }^{3-9}$

In the system of HV electric pulses, a bank of capacitors is charged using the energy obtained from an HV power supply scheme. The charged capacitor bank is allowed to discharge through the food material to be processed for generating the required high-intensity electric field in the space (containing food) between the electrodes. ${ }^{4}$

Each energy storage capacitor in the capacitor bank has the capacitance $\mathrm{C}(\mathrm{F})$ as defined by equation (1):

$$
C=\frac{\tau \sigma A}{d}
$$

where $\tau$ denotes the width of the HV electric pulse (s), $\sigma$ represents the electrical conductivity of the food material to be processed $\left(\mathrm{Sm}^{-1}\right), A$ represents the area of cross-section of each electrode surface $\left(\mathrm{m}^{2}\right), d$ is the distance between the parallel electrodes (m). The following equation (2) is used to calculate the magnitude of electric field intensity $(E)$ in $\mathrm{kV} / \mathrm{m}$ produced in the food material to be processed. ${ }^{10}$

$$
E=\frac{\text { Charging Voltage (V) }}{\text { Distance (d) between the electrodes }}
$$

The energy stored per unit volume $(w)$ in $\mathrm{J} / \mathrm{m}^{3}$ of the capacitor is denoted as equation (3), where $\varepsilon$ denotes the permittivity of food material placed between the electrodes $(\mathrm{F} / \mathrm{m})$.

$$
w=\frac{1}{2} \varepsilon E^{2}
$$

The HV switch is closed in response to a trigger signal. The charged capacitors discharge at a very fast rate through the food material placed in between a pair of electrodes kept in a processing chamber where the food is treated. ${ }^{11}$

\section{PEF system}

A pulsed electric field (PEF) supply unit also called a pulse power source is designed for $40 \mathrm{kV}$ using high dielectric constant capacitors. It is made to charge in parallel and discharged in series through a very low inductance. The heart of the unit is the Pulse Forming Network (PFN) which has a HV power supply unit, a pulse forming unit, a filtering network and a main spark gap switch. The control unit is designed to have a trigger generator that generates a trigger pulse in response to $\mathrm{a}+5 \mathrm{~V}$ command which initiates the spark gap discharge automatically. The system is designed to have a minimum load of $50 \Omega$. The $50 \Omega$ resistor is selected to avoid loading problems when high concentration juices or salt solutions are processed. A kilovolt meter (analogue) is inbuilt to record the voltage and a digital storage oscilloscope is used to record the pulse shape. An energy meter is also incorporated into the system to record the energy consumed after each trial. The schematic arrangement of the PEF system is shown in figure $\mathbf{1 .}$

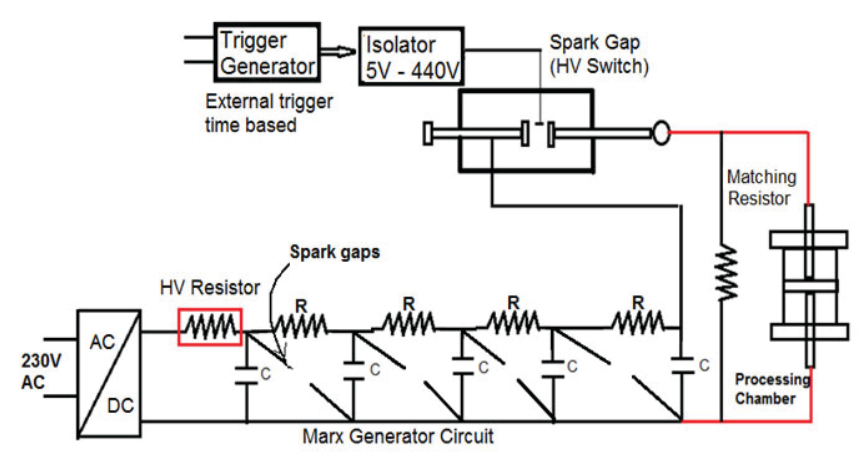

Figure 1: Schematic of PEF method of milk processing.

\section{PEF chamber}

A lab-scale PEF chamber is designed using an acrylic sheet embedded with two circular food-grade stainless steel electrodes. The PEF chamber consists of a fill valve, drain valve and adjustable electrodes. The active PEF region can be varied by adjusting the distance between the electrodes. The diameter of the electrodes is designed as $9.5 \mathrm{~cm}$. The PEF chamber is designed for batch processing which can hold approximately $100 \mathrm{ml}$ of liquid food.

The raw milk is treated at different pulse rates and different voltage levels. The parameters (voltage, distance between electrodes, and the number of pulses) are standardized by conducting many trials and by undergoing platform tests, chemical analysis, microbial analysis and nutrient analysis. The raw milk is treated with standardized parameters and packed using different packaging materials. 


\section{Packaging materials}

Food packaging plays an important role in extending the period during which the processed food will remain safe. The shelf-life of the PEF processed food product can be extended using packaging materials that are less sensitive to oxygen exposure. Some authors have reported that the headspace has higher oxygen concentration with more diminished Vitamin C levels. ${ }^{12}$ A technique called Modified Atmosphere Packaging (MAP) is used to regulate oxygen concentration in the headspace.

The factors which influence the degradation of flavour compounds are (i). oxidation, (ii). susceptibility of materials used for packaging to permeate through and absorb flavour compounds. The rate of absorption is more if both the flavour compound and the materials used for packaging have similar chemical structural configuration or similar polarity. ${ }^{13}$ For example, the volatile flavour compounds such as d-limonene and $\alpha$-pinene of orange juice are more easily absorbed by low-density polyethene (LDPE) due to the strong affinity of the non-polar hydrocarbon of LDPE to the non-polar terpene hydrocarbons present in the juice. ${ }^{14}$ However, the packaging materials can be so designed with low diffusivity and solubility to reduce the absorption of the fresh volatile flavour compounds of HV electric pulses treated food. The other polymer elements like polyvinylidene chloride (PVDC), polyethene terephthalate (PET), and ethylene vinyl alcohol (EVOH) do not easily absorb the volatile flavour compounds. The EVOH is commonly used in food packaging to help keep the air out and the flavour compounds in. However, the period during which the processed orange juice will remain safe is reduced due to the presence of oxygen in the package headspace. ${ }^{15}$ The oxygen concentration can be limited in headspace using the Modified Atmosphere Packaging technique for extending the shelf-life of foods treated by short-duration HV electric pulses.

Another effective technology used for the preservation of high voltage treated foods in the liquid state is Aseptic food packaging which can extend the shelf-life of HV treated foods compared to that of the conventionally processed food products. ${ }^{16,17}$ The aseptic food packaging technique employs plastics and laminated paper as packaging materials. However, the extension of the initial high quality of flavour, colour, and nutrients of $\mathrm{HV}$ electric pulses treated food products depends on the proper selection of packaging materials. Some authors have proposed Polyethylene as a packaging material that can provide a low barrier to oxygen. ${ }^{18-20}$ But this low barrier property of polyethene may cause instability of vitamins and the flavour compounds in the processed food products. ${ }^{18}$

Some authors reported that vitamin C, colour, and flavour compounds of $\mathrm{HV}$ treated food can be effectively maintained at $4^{\circ} \mathrm{C}$ for 112 days if the $\mathrm{HV}$ treated food is preserved in glass bottles and polyethene terephthalate (PET) bottles in which the concentrations of vitamins are higher than that in high-density polyethene (HDPE) or LDPE bottles. ${ }^{12}$

\section{Packaging materials used for the study}

The packaging materials used for the study are glass bottles, metal tins, Poly Ethylene pouches and Retort pouches respectively. The glass bottles of $200 \mathrm{ml}$ capacity are sterilized in a hot air oven at $160^{\circ} \mathrm{C}$ for half an hour. The processed samples are aseptically collected in sterile glass bottles, corked and stored in $4^{\circ} \mathrm{C}$ cold rooms as shown in figure 2(i).

The lacquered tins (pull open type) of $80 \mathrm{~mm}$ diameter and $70 \mathrm{~mm}$ height are kept in a hot air oven for half an hour and the processed samples are filled aseptically and sealed using a canning machine and stored in a $4^{\circ} \mathrm{C}$ cold room as shown in figure 2(ii). The LDPE plastic is the first grade of polyethene produced using a high-pressure process. Polyethene pouches of $200 \mathrm{ml}$ capacity with 50-micron thickness are sterilized in ultraviolet (UV) light and the processed milk samples are collected aseptically and sealed using a band sealer and stored in $4^{\circ} \mathrm{C}$ cold room as shown in figure 2(iii). Another type of food packaging called reportable pouch is made from a pre-fabricated multilayer laminate of flexible plastic and Aluminum metal foil. Here in this work, the dimension of the retort pouch consisting of Aluminium metal foil is $15 \mathrm{~cm}$ $\times 20 \mathrm{~cm}$. Retort pouches of $200 \mathrm{ml}$ capacity are sterilized under UV light and the processed milk samples are collected aseptically and sealed using a band sealer and stored in a $4^{\circ} \mathrm{C}$ cold room as shown in figure 2 (iv). The processed food products placed in retort packaging are sterile and shelf-stable.

\section{Quality control tests conducted for PEF pro- cessed milk preserved in different packages}

The temperature was recorded after each trial using a high sensitive thermocouple to check the rise in temperature after processing. The colour and odour were determined using 9 points Hedonic scale rating by 10 selected untrained panellists. A sample volume of $100 \mathrm{ml}$ of processed milk sample was given to the panellists to give their ratings in comparison with the control. In five minutes of exposure of $5 \mathrm{ml}$ of the processed milk sample in a test tube to a boiling water environment, the flakes/clots appeared on the inside of the test tube and they indicated positive for the test. A digital $\mathrm{pH}$ meter standardized using a $\mathrm{pH}$ buffer of 4.0, 7.0 and 9.2 was used to determine the $\mathrm{pH}$ value of the processed food at room temperature. The acidity in the milk was estimated by titration method using $0.1 \mathrm{~N} \mathrm{NaOH}$ solution. The titratable acidity which is the sum of natural acidity and developed acidity can be expressed in terms of percentage of lactic acid and was calculated using the values of ml $0.1 \mathrm{NaOH}$ used, normality of $0.1 \mathrm{~N} \mathrm{NaOH}$ and $\mathrm{ml}$ milk solution used in this work.

A $10 \mathrm{ml}$ of milk was pipetted out using a sterile pipette into a sterile Methylene Blue Dye Reduction Test (MBRT) test 
tube to which $1 \mathrm{ml}$ of methylene blue was added and closed with a sterile rubber cork. The test tubes were kept in the water bath at a temperature of $37 \pm 0.5^{\circ} \mathrm{C}$. Time taken for the reduction of methylene blue dye was observed. The time at which the blue colour disappeared was noted as MBR time. Total plate count was assessed for the processed and control samples of milk in different packaging materials during storage daily for 30 days. The samples were analyzed in triplicate following the methods of ISO 4833 for total plate count. Coliform was assessed for the processed and control samples of milk in different packaging materials during 30 days period of storage. The analysis of the milk samples was carried out in triplicate following the methods of ISO 16649 - 2 for coliform. The nutrients such as fat, protein, Solids-not-fat (SNF) contents and lactose were assessed in the PEF processed milk during its storage period using a milco scanner.

A 9 point Hedonic scale rating was used to measure the food acceptability. For sensory evaluation, colour, odour, and overall acceptability were assessed by selecting 10 untrained panellists. The $100 \mathrm{ml}$ samples of all the processed milk samples were presented to the panellists. The preferred samples in comparison with untreated samples were rated by the panellists. The data were analyzed by a nonparametric test called Mann - Whitney U test for comparing the median of two populations that come from the same population. The test statistic is given by equation (4):

$$
U=n_{1} n_{2}+\frac{n_{2}\left(n_{2}+1\right)}{2}-\sum_{i=n_{1}+1}^{n_{2}} R_{i}
$$

Where, $U=$ Mann - Whitney $\mathrm{U}$ test statistic

$n_{2}=$ first sample size; $n_{2}=$ second sample size

$R_{i}=$ Rank for the observation from $\mathrm{i}^{\text {th }}$ sample size

\section{Packaging of PEF processed milk}

The PEF processed milk is stored at $4^{\circ} \mathrm{C}$ in packages of different materials as shown in figure 2. The stored samples were subjected to sensory, chemical and microbial analysis at regular intervals. As glass bottles are impervious to microorganisms, pests, moisture, oxygen and odours, they did not migrate and react with milk. Sensory attributes, chemical and microbial analysis revealed a shelf life of 27 days. The tins used were double seam with push-on lids which are used to make canned foods. As the tins are impermeable to moisture, odours, light and microorganisms, the shelf life extended to 25 days. A retort pouch is made from a laminate of flexible plastic and metal foils. ${ }^{19}$ The pouches were kept under UV light before packing. Its shelf life extended to 22 days. Polyethene pouches were relatively permeable to oxygen and the shelf life of the PEF processed milk stored in polyethene pouches extended to 22 days..$^{20-21}$

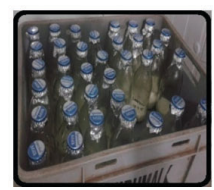

(i).

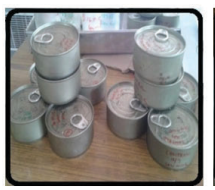

(ii).

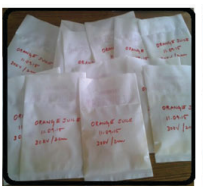

(iii).

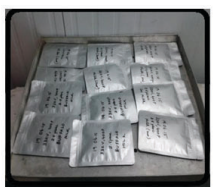

(iv).
Figure 2: PEF processed milk stored in (i). Glass bottles, (ii). Tins, (iii). Polyethylene pouches, (iv). Retort pouches.

\section{RESULTS AND DISCUSSION}

\section{Shelf-life studies of milk collected from differ-} ent sources and stored in different packages

The following figure 3 shows the comparison between different packaging materials for milk samples collected from six different places around Alamathy Redhills village. The horizontal axis represents packaging materials and the vertical axis represents the storage period in days. The processed milk samples are compared with untreated milk samples.

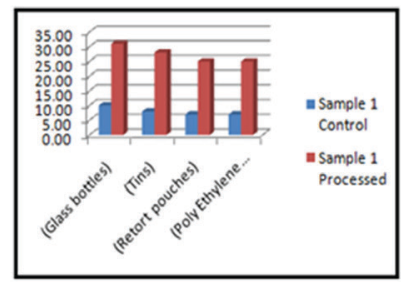

(i)

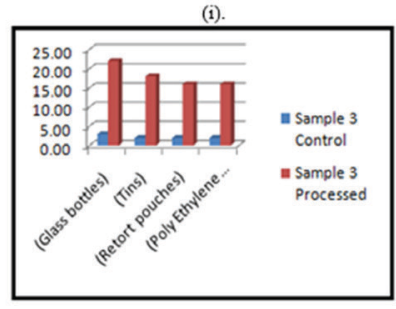

(iii).

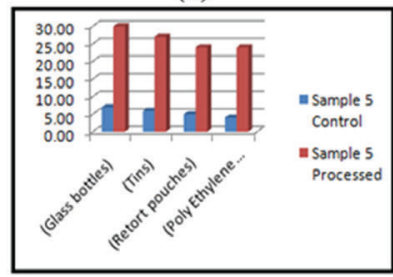

(v).

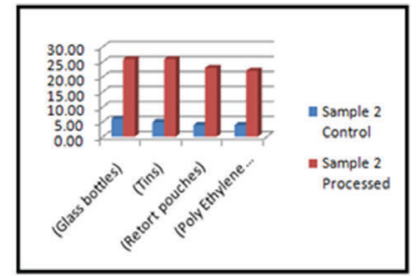

(ii).
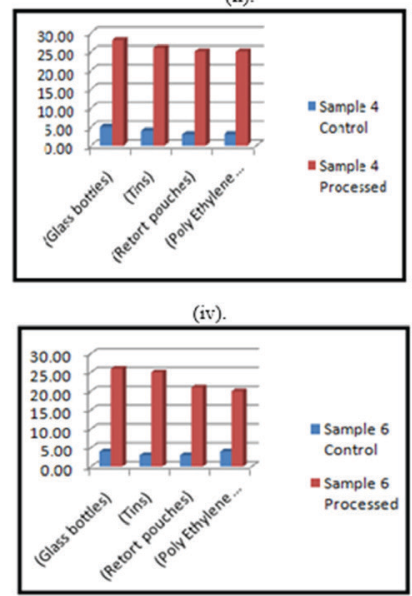

(vi).
Figure 3: Comparison of packaging materials concerning storage period for (i). sample 1, (ii). sample 2, (iii). sample 3, (iv). sample 4, (v). sample 5 , and (vi). sample 6.

\section{Statistical analysis}

In the statistical analysis of the milk sample, the distance between the electrodes, the voltage level, the number of pulses, and pulse frequency are taken as independent variables. The microbial load and shelf-life of milk samples are considered as dependent variables. The impact of 
packaging materials during shelf life studies is analyzed using a Two-way Analysis of variance (ANOVA) that tests the effect of two independent variables (control and processed samples) on a dependent variable (days). Table I shows the comparison of different packaging materials concerning the storage period for untreated and processed milk samples. Table II gives the data generated by the ANOVA test. Table III shows the comparison between the packaging materials based on the Tukey HSD test. Table IV illustrates the homogeneous subsets ' $a$ ' and 'be for different packaging materials based on Tukey HSD and Duncan's multiple range test with a 5\% level of significance.

Table I: Comparison of different packaging materials concerning storage period for untreated and processed milk samples

\begin{tabular}{llll}
$\begin{array}{l}\text { Glass bottle } \\
\begin{array}{l}\text { Control } \\
\text { (untreated) }\end{array}\end{array}$ & Processed & $\begin{array}{l}\text { Tins } \\
\text { Control } \\
\text { (untreated) }\end{array}$ & Processed \\
\hline $\begin{array}{l}5.83 \pm 2.48 \\
\text { Retort pouches }\end{array}$ & $27.17^{\mathrm{a}} \pm 3.25$ & $\begin{array}{l}4.667 \pm 2.160 \\
\text { Poly Ethylene sachets }\end{array}$ & $25^{\mathrm{ab}} \pm 3.578$ \\
$\begin{array}{l}\text { Control } \\
\text { (untreated) }\end{array}$ & Processed & $\begin{array}{l}\text { Control } \\
\text { (untreated) }\end{array}$ & Processed \\
$4 \pm 1.789$ & $22.33 \pm 3.44$ & $4 \pm 1.67$ & $22^{\mathrm{b}} \pm 3.52$ \\
\hline
\end{tabular}

Table II: Data generated by ANOVA test

\begin{tabular}{llclll} 
Source & $\begin{array}{l}\text { Type III } \\
\text { Sum of } \\
\text { squares }\end{array}$ & df & $\begin{array}{l}\text { Mean } \\
\text { square }\end{array}$ & $\begin{array}{l}\text { Fitness } \\
\text { value }\end{array}$ & Sig. \\
$\begin{array}{llclll}\text { Corrected } \\
\text { Model }\end{array}$ & $4682.917^{\mathrm{a}}$ & 7 & 668.988 & 83.018 & .000 \\
Intercept & 9918.750 & 1 & 9918.750 & 1230.869 & .000 \\
Packaging & 96.917 & 3 & 32.306 & 4.009 & .014 \\
processed & 4563.000 & 1 & 4563.000 & 566.246 & .000 \\
$\begin{array}{l}\text { Packaging * } \\
\text { processed }\end{array}$ & 23.000 & 3 & 7.667 & .951 & .425 \\
$\begin{array}{l}\text { Error } \\
\text { Total }\end{array}$ & 322.333 & 40 & 8.058 & --- & --- \\
$\begin{array}{l}\text { Corrected } \\
\text { Total }\end{array}$ & 5005.250 & 47 & --- & --- & -- \\
\hline
\end{tabular}

'a'- Correlation coefficient $=0.936$ (Adjusted value of Correlation coefficient $=0.924$ ).

'df'- degrees of freedom, 'Sig.'- Significance

The error in Mean Square is calculated as 8.058 based on observed means.
Table III: Comparison between the different packaging materials based on Tukey HSD test

Dependent variable: days

\begin{tabular}{|c|c|c|c|c|}
\hline \multirow[t]{2}{*}{ Test } & \multirow[t]{2}{*}{ Packaging } & \multirow{2}{*}{$\begin{array}{l}\text { Packaging } \\
\text { with other } \\
\text { materials }\end{array}$} & \multicolumn{2}{|c|}{$\begin{array}{l}95 \% \text { confident } \\
\text { interval }\end{array}$} \\
\hline & & & $\begin{array}{l}\text { Lower } \\
\text { bound }\end{array}$ & $\begin{array}{l}\text { Upper } \\
\text { bound }\end{array}$ \\
\hline \multirow{12}{*}{$\begin{array}{l}\text { Tukey } \\
\text { HSD }\end{array}$} & \multirow[t]{3}{*}{ Glass bottle } & 2 & -1.4397 & 4.7730 \\
\hline & & 3 & 0.2270 & 6.4397 \\
\hline & & 4 & 0.3937 & 6.6063 \\
\hline & \multirow[t]{3}{*}{ Tins } & 1 & -4.7730 & 1.4397 \\
\hline & & 3 & -1.4397 & 4.7730 \\
\hline & & 4 & -1.2730 & 4.9397 \\
\hline & \multirow{3}{*}{$\begin{array}{l}\text { Retort } \\
\text { pouches }\end{array}$} & 1 & -6.4397 & -.2270 \\
\hline & & 2 & -4.7730 & 1.4397 \\
\hline & & 4 & -2.9397 & 3.2730 \\
\hline & \multirow{3}{*}{$\begin{array}{l}\text { Polyethylene } \\
\text { sachets }\end{array}$} & 1 & -6.6063 & -.3937 \\
\hline & & 2 & -4.9397 & 1.2730 \\
\hline & & 3 & -3.2730 & 2.9397 \\
\hline
\end{tabular}

Table IV: Homogeneous subsets for different packaging materials

\begin{tabular}{|c|c|c|c|c|}
\hline \multirow[t]{2}{*}{ Test } & \multirow[t]{2}{*}{ Packaging } & \multirow{2}{*}{$\begin{array}{c}\text { No. of trials } \\
\qquad \mathrm{N}\end{array}$} & \multicolumn{2}{|c|}{ Subset } \\
\hline & & & B & $\mathbf{a}$ \\
\hline \multirow[t]{5}{*}{$\begin{array}{l}\text { Tukey } \\
\text { HSD, b }\end{array}$} & $\begin{array}{l}\text { Poly Ethylene } \\
\text { pouches }\end{array}$ & 12 & 13.0000 & --- \\
\hline & $\begin{array}{l}\text { Retort } \\
\text { pouches }\end{array}$ & 12 & 13.1667 & --- \\
\hline & Tins & 12 & 14.8333 & 14.8333 \\
\hline & Glass bottle & 12 & --- & 16.5000 \\
\hline & Sig. & --- & 0.400 & 0.484 \\
\hline \multirow[t]{5}{*}{ Duncan, b } & $\begin{array}{l}\text { Poly Ethylene } \\
\text { pouches }\end{array}$ & 12 & 13.0000 & --- \\
\hline & $\begin{array}{l}\text { Retort } \\
\text { pouches }\end{array}$ & 12 & 13.1667 & --- \\
\hline & Tins & 12 & 14.8333 & 14.8333 \\
\hline & Glass bottle & 12 & --- & 16.5000 \\
\hline & Sig. & --- & 0.143 & 0.158 \\
\hline
\end{tabular}

Statistical analysis was carried through average and percentage analysis. Two way ANOVA test was carried out by keeping the days as dependent variables and all the other facts as independent variables. Duncan's multiple range test was conducted to find the homogenous subsets. 
Statistical analysis demonstrates that the packaging materials differ significantly between them. The shelf-life of milk in glass bottles showed a significant difference when compared to tins, polyethene sachets and retort pouches. But, the retort and polyethene sachets do not differ significantly. Glass bottles attained a maximum shelf-life followed by tins. The fitness of the model is reflected through the ' $\mathrm{F}$ ' value which is significant at the $1 \%$ level. The independent variable (control sample and processed samples) also show significant variations across the four different groups which are also reflected through the ' $F$ ' values at a $1 \%$ level of significance. From homogenous subsets, Polyethylene, Retort and tins do not differ significantly at a $5 \%$ level of significance. Group 1 (Glass bottles) has a significant difference when compared to the other packaging materials such as Polyethylene, Retort and Tin.

\section{CONCLUSION}

The raw milk procured from nearby villages was processed using a pulsed electric field system and its shelf life was investigated using four different packaging materials. A voltage level of $35 \mathrm{kV} / \mathrm{cm}$ and 600 square pulses of pulse width $2.5 \mu \mathrm{sec}$ enhanced the shelf-life to 28 days when stored in glass bottles. During the shelf-life studies in different packaging materials, it was observed that there was a significant difference between glass bottles and the other packaging materials. Among the four packaging materials, glass bottles exhibited a greater shelf-life followed by tins, retort pouches and polyethene sachets.

\section{ACKNOWLEDGEMENT}

The authors acknowledge the help provided by Kwality milk foods, Kanchipuram for microbiology work and quality control lab, Aavin, Ambattur for nutrient analysis for the processed milk samples. The authors acknowledge the help provided by Dr. Z. H. Sholapurwala, Managing Director, Zeonics Systech Defence and Aerospace Engineers in carrying out the work in Pulsed Electric field Processing. Authors acknowledge the help provided by Dr. D. Ramasamy, Professor and Head, Department of Food Science and Technology, College of Food and Dairy Technology, Koduvalli, Chennai 600052 in rendering the information about packaging materials.

Conflict of Interest: The authors declare no conflict of interest associated with this work.

Source of Funding: There is no external funding agency associated with this article.

Ethical Clearance: No experiment was done on humans or animals.
Authors Contribution: Dr. G. Sujatha, Dr. T. Sivakumar, and Dr. D. Murali contributed to the design and implementation of the research work.

\section{REFERENCES}

1. Barbosa-Canovas GV, Swanson BG, Pothakamury UR, Gongora-Nieto MM, Canovas. Preservation of Foods with Pulsed Electric Fields. Chapter 6. Academic Press. London. 1999;156-171.

2. Min S, Evrendilek GA, Zhang HQ. Pulsed Electric Fields: Processing System, Microbial and Enzyme Inhibition, and Shelf-life Extension of Foods. IEEE Trans on Plasma Sci. 2007;35(1):5973.

3. Kumar Y, Patel KK, Kumar V. Pulsed Electric Field Processing in Food Technology. Int $\mathrm{J}$ Engg Studies and Tech Appr. 2015;1(2):6-16.

4. Syed QA, Ishaq A, Ur Rahman U, Aslam S, Shukat R. Pulsed Electric Field Technology in Food Preservation: A Review, J Nutri Health \& Food Engg. 2017;6(5):168-172.

5. Siemer C, Aganovic K, Toepfl S, Heinz V. Application of Pulsed Electric Fields in Food, Conventional and Advanced Food Processing Technologies. 2014;645-672.

6. Toepfl S, Siemer C, Saldana-Navarro G, Heinz V. Overview of Pulsed Electric Fields Processing for Food. Chapter 6, Emerging Technologies for Food Processing ( $2^{\text {nd }}$ Edi. $), 2014 ; 93-114$.

7. Mohamed ME, Amer Eiss AH. Pulsed Electric Fields for Food Processing Technology. Structure and Function of Food Engineering, Eiss AA. Ed. IntechOpen. London. 2012;11:275-306.

8. Nowosad K, Sujka M, Pankiewicz U, Kowalski R. The Application of PEF Technology in Food Processing and Human Nutrition. J Food Sci. and Tech, 2020;1-15.

9. Prihatini R, Saleh NM. The Stimulated Growth of Tissue Cultured Banana and Slipper Orchid as Exposed to Extremely Low Frequency Electromagnetic Field. Int J Design \& Nature and Ecodyn. 2020;15(4):491-497.

10. Pizzichemi M. Application of Pulsed Electric Fields to Food Treatment. Nuclear Physics B - Procs. Supplements. 2007;172: 314-316.

11. Qin BL, Pothakamury UR, Barbosa-Canovas GV, Swanson BG. Nonthermal Pasteurization of Liquid Foods using High-intensity Pulsed Electric Fields. Crit Rev Food Sci and Nutri. 1996;36(6): 603-627.

12. Ayhan Z, Yeom HW, Zhang QH, Min DB. Flavour, Color, and Vitamin C Retention of Pulsed Electric Field Processed Orange Juice in Different Packaging Materials. J Agri Food Chemis. 2001;49(2):669-674.

13. Landois-Garza J, Hotchkiss JH. Plastic Packaging can cause Aroma Sorption. Food Engg. 1987;4: 39-42.

14. Islam MA, Ahmad SA, Sarkar A. Biochemical Composition and Shelf Life Study of Mixed Fruit Juice from Orange and Pineapple. J Envir Sci and Natural Res. 2014;7(1): 227-232.

15. Balasubramanian S, Sharma R. Aseptic Packaging of Food and Food Products. Processed Food Industry, 2009;1-7.

16. Piringer OG, Baner AL. Plastic Packaging Materials for Food: Barrier Function, Mass Transport, Quality Assurance, and Legislation. Wiley, 2008;79-95.

17. Van Willige RWG, Linssen JPH, Voragen AGJ. Influence of Food Matrix on Absorption of Flavour Compounds by Linear Low-density Polyethylene: Proteins and Carbohydrates. J Sci of Food and Agri. 2000;80(12):1779-1789.

18. Indian Standard Polyethylene Pouches for Packaging Liquid Milk - Specification (Second Revision). BIS 2007, 1-4. 
19. Ahvenainen R. Novel Food Packaging Techniques, A Volume in Woodhead Publishing Series in Food Science, Techn Nut. 2003.

20. Botina ABL, Garzia MMC, Romero BY. Pre- and Post-harvest Factors that Affect the Quality and Commercialization of the Tahiti Lime. Scientia Horticulturae, 2019;257:1-10.
21. Lu J, Xiao J, Da-Jin Y, Zhu-Tian W, Jiang D, Fang CR, Yang J. Study on Migration of Melamine from Food Packaging Materials on Markets. Biomed Envt Sci. 2009;22(2):104-108. 